\title{
The Positive Outlook Of The Last In First Out Inventory Methods
}

Peter Harris, New York Institute of Technology, USA

Anthony Harris, CUNY-Queens College, USA

\begin{abstract}
Until very recently, the Last In First Out method (LIFO) was under severe scrutiny from the financial community, and its repeal as an acceptable accounting method seemed imminent. There were pressures from the Securities and Exchange Commission and the International Financial Accounting Standards Board to standardize accounting standards worldwide. In addition, there were political pressures imposed by US Congress to raise additional revenues. Both groups strongly oppose LIFO. However, an SEC Report issued in July 2012 has greatly renewed the lifeline of LIFO indefinitely. In the unlikely case of its ultimate repeal, the author presents some tax opportunities available in this transition period.
\end{abstract}

Keywords: LIFO; IFRS; US GAAP; SEC July 2012 Report

\section{INTRODUCTION}

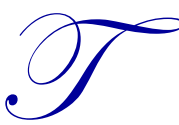

he Last in First out (LIFO) method has been an acceptable, popular accounting method since its inception in 1939. Since then, many have and continue to argue against LIFO as a viable, economic accounting method. Until recently, LIFO faced a possibility of its elimination by the year 2015, as

political forces coming from the International Financial Accounting Standards Board, the world financial community and the US administration strongly oppose this method. The International Financial Reporting Standards (IFRS) prohibits LIFO as an acceptable accounting method, and the Obama administration proposed in its 2010 budget to repeal LIFO altogether in the future. However, given a recent unprecedented report issued by the SEC in July 2012, which questioned IFRS use altogether, stating that there are too many gaps inherent in this regime, LIFO's repeal is now very unlikely. Part 2 will give a literature review of LIFO's tax advantages and financial statement limitations. Part 3 will examine the current state of LIFO, and Part 4 will investigate the future of LIFO, while Part 5 will provide recommended tax planning opportunities assuming the possible repeal of LIFO. The conclusion section Part 6, will also recommend areas for future research.

\section{LITERATURE REVIEW}

The tax advantages associated with LIFO have been documented by tax laws, research, literature and Congress. Internal Revenue Code (IRC) 472 allows for the Last in First Out method of inventory since its inception date in 1939. Computationally, as the price of inventory increases, lower income will result under LIFO when compared to all other inventory methods, resulting in a lower tax payment. This tax advantage has led to the criticism of LIFO resulting in an unfair tax loophole advantage for a few beneficial industries; leading to poor and inefficient management of inventories, the need to maintain two sets of accounting records, and finally flawing the balance sheet presentation.

White, Sondhi and Fried (2008), state that due to the tax advantages associated with LIFO resulting in greater cash flows, the choice of inventory method should point towards LIFO. Dopuch and Pincur (1988) found that the taxation effect was the primary reason a company chose LIFO.

To obtain the tax benefit, three elements have to be satisfied. First, there has to be a scenario of; increasing inventory prices (inflation); second, a buildup or increase in inventory, known as a LIFO reserve; and finally, there has to be an income tax. LIFO use in an inflationary environment will result in expensing the most current higher cost 
inventory purchases against revenue, resulting in the lowest possible income total. The greater the inflation environment, the more pronounced is the tax benefit. This was observed in the early to mid-1970, a period of double digit inflation in the U.S, when more than 400 publically U.S companies elected to change their inventory method to LIFO.

The tax advantage of LIFO is also dependent on inventory additions or buildups, known as reserves. This has resulted in poor inventory asset management and suboptimal business behavior as observed by Trackel and Trezevant (1994).

The US government has estimated that presently less than $15 \%$ of publically traded companies use LIFO, and that the corporate tax rate of $35 \%$ can be reduced to $30.5 \%$ if all of the corporate tax loopholes such as LIFO were eliminated. The elimination of LIFO is expected to add 100 Billion Dollars in US tax revenue over the next ten years according to the US government. This figure is very optimistic and inflated when one considers that the overall LIFO reserve is 100 Billion dollars (Compustat), so at a 35 percent tax rate, this LIFO reserve figure will have to triple over the next ten years to meet such projections. A more realistic figure will be 35 million dollars added to tax revenue to the US government over an eight year period.

As a defense to LIFO users, non LIFO firms have the option to adapt the Lower of Cost or Market Method (LCM). LCM allows inventory to be valued below cost if cost exceeds market value. Market value is defined as replacement cost and such valuation can be made on an item by item basis. As an example, a company may obtain a tax advantage prior to the sale of their inventory by the adoption of a non LIFO- LCM method. Given that LIFO adopters tend to experience increasing inventory market values, this benefit is not really viable to them. Additionally, I believe pressures in the future by Congress will eliminate this potential advantage if LIFO is repealed, as it represents yet another tax loophole, primarily for non LIFO users. This method is used by industries which have obsolete type inventories like computer, chip and food.

The tax deferred argument under FASB 109 can be made in defense of LIFO. One may argue that this LIFO reserve represents a temporary tax difference which will be paid to the US government in the future, when this difference reverses causing higher taxable income. This then is similar to differences resulting in depreciation totals between book and tax purposes, which lead to a deferred tax liability. This is a weak argument as research has shown that when future earnings expectations are not available, companies opt out of LIFO and therefore, no reversal of this deferred tax liability is ever realized.

Finally, one needs to question whether the elimination of LIFO will have any dent on the Federal Deficit which at present is 16.5 trillion dollars. Repealing LIFO will add per my projection, 35 billion in tax revenue which will reduce the deficit a meager one quarter of one percent. LIFO is not in any way the culprit of this deficit, and the regulators realize this, as they have eased their attack on LIFO in this most recent time. Too many tax loopholes exist, many of which are political in nature which adds to the problem of a fair tax code. A comprehensive tax policy is argued as a good starting point to address this lingering and critical problem. However, interest groups can put a quick end to this potential and hopeful development.

\section{RECENT DEVELOPMENTS AND CURRENT STATE OF LIFO}

For the period 2006 to early 2012, LIFO was facing pressures from both: the International Reporting Standards Board in cooperation with the SEC, and the U.S. Congress for its possible complete elimination by the year 2014.On November 15, 2007, the Securities and Exchange Commission (SEC) exempted foreign firms from including reconciliation from International Financial Reporting Standards (IFRS) to U.S Generally Accepted Accounting Principles, (U.S. GAAP) when filing on U.S. Stock exchanges. Foreign public firms were permitted until 2010 to file using the International Financial Reporting Standards (IFRS) without reconciliation to U.S. GAAP as previously required. This move created a mandate to converge IFRS and U.S. GAAP and financial statement requirements (SEC, 2007)

On June, 18, 2008 the SEC issued a press release stating that the world's securities regulators are uniting to increase their oversight of international accounting standards. There were plans set forth by the SEC and the IFRS to 
standardize accounting standards, on a worldwide basis with a target date set for periods ending after December 31, 2014. IFRS convergence in the US seemed manifest. Under IFRS rules, LIFO is not a permitted acceptable accounting method. The Obama Administration had proposed in its 2010 budget to repeal LIFO altogether in an attempt to generate greater tax revenues.

On January 1, 2011, more than 100 countries have adapted IFRS or a variation, including our neighboring country Canada. IFRS curriculum has also penetrated the college curriculum of US universities as the major testing agencies have greatly incorporated IFRS as required topic coverage. The Uniform CPA exam tests IFRS and the CFA examination has eliminated US GAAP altogether from the curriculum and solely tests IFRS. International Accounting courses have become the norm in US universities. So what happened to change this thinking?

First, the development of a financial crisis in Europe questioned whether accounting information really causes economic downturns. The European Community adopted IFRS but it did not prevent a financial crisis. Secondly, different variations of IFRS were adopted for use by many countries, thus raising the issue of comparability. Third, and most importantly was a report issued by the SEC in July 2012 questioning IFRS as a viable accounting system, and stating that it has too many "gaps"?

The SEC questioned a number of items, starting with adequate funding needs in their continued success. A lack of reporting consistency among IFRS users is also a major SEC concern. Significant accounting reporting gaps were cited such as the treatment of contingency losses. Additionally, the report noted that several items of accounting are too much removed from US GAAP treatment that convergence seems unlikely. These items include, inventory costing, contingencies, deferred income taxes, depreciation and the presentation of Fixed Assets. These differences seem irreconcilable and in the case of LIFO, the issue relates to taxation, rather than accounting policy. Most significantly in this report, the SEC announced that it has no target date, if any, for IFRS convergence. Clearly, the SEC is in no rush and non-enthusiastic about convergence, which is not likely to happen anytime in the intermediate future. These developments have put LIFO repeal on the backburner, and the result is that the political pressures against LIFO have eased in a significant manner and the likelihood of its eventual repeal anytime soon is very unlikely

\section{THE FUTURE OF LIFO}

There are four possibilities of LIFO going forward, and illustrated as follows:

\begin{tabular}{c|c|c}
\hline Case & Financial Reporting Purposes & Tax Purposes \\
\hline 1 & Yes & Yes \\
\hline 2 & No & Yes \\
\hline 3 & Yes & No \\
\hline 4 & No & No \\
\hline
\end{tabular}

In case 1, LIFO would continue as present. Although dual resistance from IFRS and Congress exist, recent developments and charges against senator Rangel, coupled with the continued weakness in the worldwide economy makes the status quo a reality. Although the continued use of LIFO will greatly and potentially hinder the goal of uniform financial reporting going forward, the ultimate goal here has moved to convergence and not uniformity, adding to the real probability of continued LIFO use in the USA. Compromises between US GAAP and IFRS in my opinion will be the norm rather than the exception going forward.

In case 2, allowing LIFO for tax purposes and not for financial reporting purchases represents the best of both world, as a company report the highest income for financial reporting purposes and pay the least amount of tax. The scenario would effectively eliminate the LIFO conformity requirement. The likelihood of this happening is most unlikely and not feasible.

In case 3, the worst of both worlds for a company; that is, the lowest income for financial reporting and the highest tax payment. This scenario is also not feasible. 
Case 4 represents the complete elimination of LIFO. This will only occur if LIFO is eliminated at the tax level. If so, then it will be eliminated for financial reporting purposes, as the advantage for business purposes would not exist. Given the SEC's non commitment to IFRS adaption in the US and the spiraling US deficit which now exceeds 16.5 trillion Dollars, LIFO is safe, and it is unlikely that any repeal will occur in the future. When coupled with the continuance of the worldwide economic recession, it is very unlikely that LIFO will not be seriously addressed again until well beyond the next US election in 2016. The author's prediction, then, is a status quo on LIFO into the foreseeable future."

\section{TAX PLANNING OPPORTUNITIES AVAILABLE FOR THE CURRENT USERS OF LIFO}

Assuming the repeal of LIFO, or a switch from LIFO voluntarily which is more suitable, what are some of the tax planning opportunities available to taxpayers to help ease in this transition?

1. Extended Payment Adjustment Period: Under current tax rules, if a taxpayer changes its inventory method from LIFO to another acceptable method which results in a higher taxable income, the additional tax is payable over a period of eight years.

2. Under the current Obama Administration's 2010 Budget Proposal, the difference would be spread to taxable income and payable over eight years. Consequently, the termination of LIFO would be mitigated as the resulting extra tax would be payable to the tax authorities over an eight year period. In an atmosphere of economic slowdown, many entities have chosen this route.

3. Lower inventory amounts and switch to a Just in Time Inventory purchasing system. Lower inventory levels will somewhat insulate against increased income (added income tax payments), and will also lead to a better inventory management approach, resulting in lower carrying costs.

\section{CONCLUSION}

The probability of the elimination of LIFO as an acceptable accounting method is very unlikely any time in the foreseeable future. This paper addressed the present and future outlook of LIFO. In the author's opinion, LIFO will continue as is in the indefinite future, and will not be addressed again until after the 2016 presidential election. Worldwide financial reporting will continue to have differences with the US, and whether SEC workings with the International Reporting Board continue remains to be seen. In the event of LIFO's eventual repeal, the author recommends several tax strategies to help ease the burden of this change. Additional research examining the managerial, non-tax advantages of FIFO when compared to LIFO should be addressed, as well as the effect of the US deficit by the continued allowance of LIFO use.

\section{AUTHOR BIOGRAPHY}

Peter Harris, CPA, CFA is a Professor and Chair of the Accounting and Finance department at the New York Institute of Technology. Previously, he had worked for Ernst and Young LLP. He is an author of over 60 refereed journal articles and 150 intellectual contributions. He has presented and continues to present seminars to nationally and globally audiences on topics relating to financial reporting and taxation. He is a member of several professional organizations. He can be reached at pharris@nyit.edu.

Anthony Harris, B.A, CPA Candidate (completed the CPA exam). Anthony Harris has recently passed all four parts of the CPA examination on his first sitting. He recently graduated with a B.A Degree in Accounting from CUNY-Queens College, and has completed 151 credits towards his degree. He also attended Stevens Institute of Technology. He was an honor student during each of his five years of study, and graduated Summa Cum Laude, and near the top of his class. He is planning to attend graduate school, and attend the work force in public accounting to gain the work experience requirement to earn him the CPA license.

\section{REFERENCES}

IRC 472

The SEC Report, July, 2012

The Analysis and Uses of Financial Statements, White, Sondhi, Fried, Wiley, 4rd Edition, 2012. 